\title{
Results of Endoscopic Surgery in Patients with Pituitary Adenomas : Association of Tumor Classification Grades with Resection, Remission, and Complication Rates
}

\author{
Buruc Erkan, ${ }^{1, *}$ Ozan Barut, ${ }^{2}$ Ahmet Akbas, ${ }^{3}$ Ebubekir Akpinar, ${ }^{2}$ Yasemin Sefika Akdeniz, ${ }^{4}$ Osman Tanriverdi, ${ }^{2}$ Omur Gunaldi \\ Department of Neurosurgery, Umraniye Research \& Training Hospital, Health Sciences University, Istanbul, Turkey \\ Department of Neurosurgery, ${ }^{2}$ Bakirkoy Research \& Training Hospital for Psychiatry, Neurology, and Neurosurgery, Health Sciences Univer- \\ sity, Istanbul, Turkey \\ Department of Neurosurgery, ${ }^{3}$ Taksim Research \& Training Hospital, Health Sciences University, Istanbul, Turkey \\ Division of Endocrinology and Metabolism, ${ }^{4}$ Department of Internal Medicine, Bakirkoy Dr. Sadi Konuk Training and Research Hospital, Health \\ Sciences University, Istanbul, Turkey
}

Objective : The endoscopic endonasal transsphenoidal approach is a widely-used method for the surgical treatment of pituitary adenomas. We aimed to evaluate the results of endoscopic surgery by comparing preoperative classification methods and investigating their relationship with postoperative resection and remission rates and complications.

Methods : We retrospectively reviewed the medical records of 236 patients (118 males) who underwent surgery for pituitary adenomas. Preoperative Knosp classification, tumor size (TS), suprasellar extension (SSE), postoperative resection and remission rates, and complications were evaluated.

Results : The follow-up period was 3 months to 6 years. The patients' ages ranged between 16 and 84 years. Endocrinologically, 114 patients (48.3\%) had functional adenoma (FA), and 122 patients (51.7\%) had non-functional adenoma (NFA). Among the FA group, 92 (80.7\%) showed remission. A statistically significant difference was found between patients with and without remission in terms of the Knosp, TS, and SSE classifications $(p<0.01)$. Knosp, TS, and SSE classification grades were found to be correlated with the resection rates $(p<0.01)$. Meningitis was seen in seven patients $(3.0 \%)$, diabetes insipidus in 16 (6.9\%; permanently in two [0.9\%]), and rhinorrhea in $19(8.1 \%)$. Thirty-six patients (15.3\%) developed pituitary insufficiency and received hormone replacement therapy.

Conclusion : The resection categories and remission rates of FAs were directly proportional to the adenoma sizes and Knosp grades, while the degree of suprasellar growth further complicated resection and remission rates. Adenoma sizes less than $2 \mathrm{~cm}$ and SSEs less than $1 \mathrm{~cm}$ are associated with favorable remission and resection rates.

Key Words : Pituitary adenoma $\cdot$ Tumor grade $\cdot$ Endoscopic surgical procedure $\cdot$ Follow-up studies.

- Received : July 17, 2020 •Revised : October 6, 2020 •Accepted : October 7, 2020

- Address for reprints : Buruc Erkan

Department of Neurosurgery, Basaksehir Cam and Sakura City Hospital, Basaksehir Olimpiyat Bulvarı Yolu, 34480 Basaksehir, Istanbul, Turkey

Tel : +90 507992 33 34, Fax : +90 21290960 00, E-mail : burucerkan@hotmail.com, ORCID : https://orcid.org/0000-0001-8586-0613

${ }^{*}$ Current affiliation : Department of Neurosurgery, Basaksehir Cam and Sakura City Hospital, Istanbul, Turkey

This is an Open Access article distributed under the terms of the Creative Commons Attribution Non-Commercial License (http://creativecommons.org/licenses/by-nc/4.0) which permits unrestricted non-commercial use, distribution, and reproduction in any medium, provided the original work is properly cited. 


\section{INTRODUCTION}

Treatments for pituitary adenomas aim to eliminate pressure on the surrounding tissue and pressure-related effects, and to achieve hormonal remission ${ }^{12,13,17)}$. In the 1990 s, advances in endoscopic instruments enabled the use of the endoscopic transsphenoidal approach for pituitary adenoma surgery $^{26,27)}$.

According to Knosp classifications of pituitary adenomas, tumor size (TS) and their suprasellar extension (SSE) have been used for preoperative planning, prediction of possible outcomes, and the evaluation of surgical outcomes. Although there is no clear evidence that these classifications are associated with tumor resection and remission rates, studies are suggesting this is the case $\mathrm{e}^{6,16,18,23,25,26)}$.

In this study, we examined the associations between preoperative Knosp, TS, SSE classifications with postoperative resection and remission rates, complications, and results obtained in 236 patients who underwent full endoscopic endonasal transsphenoidal surgery (EETS).

\section{MATERIALS AND METHODS}

The study was conducted retrospectively after obtaining permission from the Ethics Committee of Health Sciences University (19 Apr 2018; 71211201-000-14131). All procedures performed in studies involving human participants were in accordance with the ethical standards of the institutional research committee and with the 1964 Helsinki declaration and its later amendments or comparable ethical standards.

Patients were evaluated by endocrinology and ophthalmology specialists. Pituitary hormone levels and visual field examinations were performed. Patients with clinically functional adenoma (FA) were re-evaluated and prepared for operation. FAs were classified as acromegaly, Cushing's disease, prolactinoma, and thyroid-stimulating hormone-secreting pituitary adenoma (TSHOMA).

\section{Surgical procedure}

All patients underwent full EETS, as described by Jho and Carrau ${ }^{20)}$. The first 15 patients were operated on under the supervision of an otolaryngologist. We undertook a binostril approach in order to provide a wider working area, and all op- erations were performed with the help of a rigid endoscope with $0^{\circ}$ and $30^{\circ}$ angled lenses. After choana and sphenoid ostium were visualized as anatomic landmarks, posterior septectomy and anterior sphenoidotomy were carried out with a high-speed drill. Following the identification of the optic and carotid protuberances, a high-speed drill and Kerrison rongeurs were used to open the sellar floor. An intraoperative Doppler ultrasonography device was used routinely in all operations for the visualization and monitoring of carotid artery. After medial portions of the carotid arteries were identified, the dura mater is opened using microscissors, and the adenoma was visualized. The tumor was removed using microsuction cannulas and pituitary curettes while endoscope was inserted into the newly opened space, allowing the direct visualization of remaining adenoma and the normal pituitary gland tissue. The removal of macroadenomas with parasellar extension and fibrotic consistency requires a wider opening of sella, and a thorough resection process of the remaining tumor tissue after the removal of the main adenoma. For the tumors with a cavernous invading tumor portion, we adopted the transsphenoidal transsellar approach, and removed the residual tumor as much as possible through a window on the medial wall of the cavernous sinus. We used the micro Doppler probe, and great care was taken not to injure the medial wall of cavernous sinus.

\section{Radiological evaluation}

All patients underwent, paranasal sinus tomography, and magnetic resonance imaging (MRI) preoperatively. The patients were evaluated according to the following three classifications using MRI measurements : 1) classification according to Knosp et al. ${ }^{25)}$ over the medial and lateral line of the internal carotid artery. 2) TS classification of the mass from the inferior to the superior, as used in previous studies ${ }^{18,23)}$. And 3) SSE classification, defined as the extension of the adenoma superior to planum sphenoidal ${ }^{18)}$.

Pituitary MRI performed 3 months postoperatively was used to determine the adenoma resection rate. The following rates were used : 100\% indicated total, 90-100\% near-total, and $90-10 \%$ subtotal resection, while $<10 \%$ was determined as biopsy ${ }^{6,22)}$.

\section{Pathological evaluation}

Routine histopathological and immunohistochemical ex- 
aminations were performed at the same center.

\section{Postoperative evaluation}

Patients were routinely monitored via pituitary MRIs and endocrinological follow-ups after 24 hours, 3 months, 1 year, and annually thereafter. For Cushing's disease, blood cortisol levels below $2 \mu \mathrm{g} / \mathrm{L}$ were accepted as early postoperative remission. Patients with Cushing's disease were considered to be in late postoperative remission, if : 1) 24-hour urinary free cortisol levels were below or within the normal range; 2) night-time salivary cortisol values were under $0.2 \mathrm{pg} / \mathrm{dL}$ or 3 ) serum cortisol levels were below $1.8 \mathrm{mcg} / \mathrm{dL}$ during the $1 \mathrm{mg}$ dexamethasone suppression test.

Patients were classified as being in remission criteria for acromegaly if growth hormone $(\mathrm{GH})$ level was $<1 \mathrm{ng} / \mathrm{mL}$ after oral glucose tolerance test, and insulin growth factor 1 was within or lower than the normal limits according to age and gender criteria ${ }^{13}$. For prolactinoma patients, a post-surgery serum prolactin level of $20 \mathrm{ng} / \mathrm{mL}$ indicated that the disease was under control. TSHOMA patients were considered endocrinologically-cured if they had normal levels of T3 and free T4 and thyroid-stimulating hormone post-surgery. We considered the early and late remission periods for FA to be 3 months and 1 year, respectively.

In cases of postoperative rhinorrhea, three different treatment methods were preferred : 1) 5-10 mL/h cerebrospinal fluid drainage for 3-5 days with lumbar drain placement, 2) EETS to repair the sella anterior wall using the subcutaneous fat tissue taken from the abdomen and abdominal anterior wall fascia grafts along with a tissue adhesive (Tissel ${ }^{\circledR}$; Baxter Healthcare Ltd Caxton Way, Thetford, England), and 3) a combination of both methods.

\section{Statistical analysis}

Descriptive statistical methods were used to evaluate the data. To compare qualitative data, we used the chi-squared test and Fisher's exact chi-square test when the expected frequencies were met and not met, respectively. The Z-test was used to determine the source of the difference. For two-group comparisons, we used t-tests and the Kruskal-Wallis test when parametric assumptions were met and not met, respectively. The Dufner test with a Bonferonni correction was used to determine the source of difference. When necessary, Bonferroni corrections were used. Statistical analyses were performed us- ing SPSS version 24 for Windows (IBM Corp., Armonk, NY, USA), and $p$-values $<0.05$ and $<0.01$ were considered statistically significant.

\section{RESULTS}

The study included 236 patients (118 males and 118 females) who underwent EETS between 2014 and 2018. The patients' age ranged from 16 to 84 years (mean, $47.56 \pm 15.14$; median, 47). Among the enrolled patients, 207 (87.7\%) were newly-diagnosed, and 29 (12.3\%) had recurrent adenomas. Endocrinologically, 114 patients (48.3\%) had FA, and 122 patients (51.7\%) had NFA before the operation (Table 1).

We then examined whether endocrinological remission was achieved in patients with FA and evaluated the postoperative resection rates. Among the 114 patients with FA, 92 (80.7\%) showed remission. No patients showed early remission and then later developed relapse. Of the 16 patients with acromegaly who did not achieve hormonal control, 14 underwent medical treatment and two underwent adjuvant radiotherapy and were subsequently not followed-up with. Of the four patients with Cushing's disease who did not achieve hormonal control, one patient had a second endoscopic procedure and obtained disease control, one patient underwent an operation and was followed-up within another center, and two patients were not followed-up with. The two patients with prolactinomas who did not achieve hormonal control after endoscopic resection were referred for medical treatment. In the subgroup of patients with partial NFA resection, 13 underwent a second endoscopic surgery, and no individuals presented with symptoms during the follow-up period. Four patients with NFA had a mass smaller than $1 \mathrm{~cm}$ and underwent a biopsy as opposed to resection due to radiological findings outlining the pathological differences from a pituitary adenoma.

There was a significant difference in remission rates between Knosp classification groups $\left(x^{2}=19.851, p<0.01\right)$. Specifically, compared to patients classified as Knosp grade 3 and 4 , the proportion of patients classified as Knosp grade 0, 1, and 2 was higher among those with remission than those without (Table 2).

There was a significant difference in remission rates according to the TS classifications $\left(x^{2}=9.96, p<0.05\right)$. Using a Z-test with a Bonferroni correction, we found that remission rates were significantly lower in patients classified as TS grade 3 
Endoscopic Surgery in Pituitary Adenomas | Erkan B, et al.

Table 1. Number and proportions of patients according to TS, SSE, and Knosp grades, in terms of endocrine diagnosis

\begin{tabular}{|c|c|c|c|c|c|}
\hline & $\begin{array}{c}\text { NFA } \\
(n=122)\end{array}$ & $\begin{array}{l}\text { Acromegaly } \\
\quad(n=62)\end{array}$ & $\begin{array}{l}\text { Cushing } \\
(n=36)\end{array}$ & $\begin{array}{l}\text { Prolactinoma } \\
\qquad(n=14)\end{array}$ & $\begin{array}{l}\text { TSHOMA } \\
(n=2)\end{array}$ \\
\hline \multicolumn{6}{|l|}{ Total $(n=236)$} \\
\hline \multicolumn{6}{|l|}{ TS } \\
\hline $1(n=50)$ & $4(3.3)$ & $20(32.3)$ & $25(69.4)$ & $0(0.0)$ & $1(50.0)$ \\
\hline $2(n=75)$ & $35(28.7)$ & $23(37.1)$ & $10(27.8)$ & $7(50.0)$ & $0(0.0)$ \\
\hline $3(n=20)$ & $13(107)$ & $6(9.7)$ & $1(2.8)$ & $0(0.0)$ & $0(0.0)$ \\
\hline $4(n=58)$ & $42(34.4)$ & $12(19.4)$ & $0(0.0)$ & $4(28.6)$ & $0(0.0)$ \\
\hline $5(n=33)$ & $28(23.0)$ & $1(1.6)$ & $0(0.0)$ & $3(21.4)$ & $1(50.0)$ \\
\hline \multicolumn{6}{|l|}{ SSE } \\
\hline$A(n=158)$ & $59(48.4)$ & $53(85.5)$ & $35(100)$ & $9(64.3)$ & $1(50.0)$ \\
\hline$B(n=46)$ & $35(28.7)$ & $8(12.9)$ & $0(0.0)$ & $3(21.4)$ & $0(0.0)$ \\
\hline$C(n=23)$ & $21(17.2)$ & $1(16.1)$ & $0(0.0)$ & $1(7.1)$ & $0(0.0)$ \\
\hline$D(n=9)$ & $7(5.7)$ & $0(0.0)$ & $0(0.0)$ & $1(7.1)$ & $1(50.0)$ \\
\hline \multicolumn{6}{|l|}{ Knosp } \\
\hline $0(n=36)$ & $2(1.6)$ & $14(22.6)$ & $18(50.0)$ & $1(7.1)$ & $1(50.0)$ \\
\hline $1(n=75)$ & $35(28.7)$ & $22(35.5)$ & $14(38.9)$ & $4(28.6)$ & $0(0.0)$ \\
\hline $2(n=55)$ & $35(28.7)$ & $15(24.2)$ & $2(5.6)$ & $2(14.3)$ & $0(0.0)$ \\
\hline $3(n=40)$ & $33(27.0)$ & $3(4.8)$ & $2(5.6)$ & $2(14.3)$ & $0(0.0)$ \\
\hline $4(n=30)$ & 17 (13.9) & $8(12.9)$ & $0(0.0)$ & $5(35.7)$ & $1(50.0)$ \\
\hline
\end{tabular}

Values are presented as number (\%). TS : tumor size, SSE : suprasellar extension, NFA : non-functional adenoma, TSHOMA : thyroid-stimulating hormone-secreting pituitary adenoma

Table 2. Comparison of patients with FA according to Knosp grades $0 / 1 / 2$ and $3 / 4$ in terms of remission status

\begin{tabular}{|c|c|c|c|c|}
\hline & Knosp 0/1/2 & Knosp 3/4 & $x^{2}$ & $p$-value \\
\hline Remission $(n=114)$ & & & 19.851 & $<0.001^{*}$ \\
\hline No $(n=22)$ & $11(11.7)$ & $11(55.0)$ & & \\
\hline Yes $(n=92)$ & $83(88.3)$ & $9(45.0)$ & & \\
\hline
\end{tabular}

Values are presented as number (\%). Fisher exact chi square. ${ }^{*} p<0.01$. FA : functional adenoma

$(\mathrm{z}=1.99, p<0.05)$.

According to the SSE classification, the proportion of patients with remission was higher among those classified as SSE grade A compared to grade B (subgroups were compared using a Ztest with a Bonferroni correction, $\mathrm{z}=2.88, p=0.003$; Table 3).

Regarding TS, there was a significant difference between groups in terms of the amount of resection $\left(x^{2}=92.16, p<0.001\right)$. Subgroups were compared using a Z-test with a Bonferroni correction $(p<0.01$; Table 4$)$. The proportion of patients with total resection was significantly higher than that of patients with near-total and subtotal resection among those with TS grade 1 (total vs. near total : $\mathrm{z}=2.98, p<0.001$; total vs. subtotal : $\mathrm{z}=3.78, p<0.001$ ) and grade 2 (total vs. near total $: \mathrm{z}=3.50$, $p<0.001$; total vs. subtotal : $z=3.57, p<0.001)$. In contrast, the proportion of patients with total resection was significantly lower than that of patients with near-total and subtotal resection among those with TS grade 4 (total vs. near total : $z=2.30$, $p<0.05$; total vs. subtotal : $z=3.96, p<0.001$ ) and grade 5 (total vs. near total : $\mathrm{z}=6.40, p<0.001$; total vs. subtotal : $\mathrm{z}=7.75, p<0.01$ ).

Regarding the SSE variable, there was a significant difference in terms of the amount of resection $\left(x^{2}=59.68, p<0.001\right)$. Subgroups were compared using a Z-test with a Bonferroni correction $(p<0.01)$. Among patients with SSE grade A, the proportion of patients with total resection was significantly 
J Korean Neurosurg Soc 64 | July 2021

Table 3. Comparison of patients with FA according to TS, SSE, and Knosp grades, in terms of remission status

\begin{tabular}{|c|c|c|c|c|}
\hline & No $(n=22)$ & Yes $(n=92)$ & $x^{2}$ & $p$-value \\
\hline \multicolumn{5}{|c|}{ Remission $(n=114)$} \\
\hline TS & & & 9.964 & $0.027^{*}$ \\
\hline $1(n=46)$ & $7(15.2)$ & $39(84.8)$ & & \\
\hline $2(n=40)$ & $4(10.0)$ & $36(90.0)$ & & \\
\hline $3(n=7)$ & $3(42.9)$ & $4(57.1)$ & & \\
\hline $4(n=16)$ & $6(37.5)$ & $10(62.5)$ & & \\
\hline $5(n=5)$ & $2(40.0)$ & $3(60.0)$ & & \\
\hline SSE & & & 10.058 & $0.008^{\dagger}$ \\
\hline$A(n=99)$ & $15(15.2)$ & $84(84.8)$ & & \\
\hline$B(n=11)$ & $6(54.5)$ & $5(45.5)$ & & \\
\hline$C(n=2)$ & $1(50.0)$ & $1(50.0)$ & & \\
\hline$D(n=2)$ & $0(0.0)$ & $2(100)$ & & \\
\hline Knosp & & & 18.239 & $0.001^{\dagger}$ \\
\hline $0(n=34)$ & $5(14.7)$ & 29 (85.3) & & \\
\hline $1(n=40)$ & $3(7.5)$ & 37 (92.5) & & \\
\hline $2(n=20)$ & $3(15.0)$ & $17(85.0)$ & & \\
\hline $3(n=7)$ & $3(42.9)$ & $4(57.1)$ & & \\
\hline $4(n=13)$ & $8(61.5)$ & $5(38.5)$ & & \\
\hline
\end{tabular}

Values are presented as number (\%). Fisher exact chi square. ${ }^{*} p<0.05 .{ }^{\dagger} p<0.01$. FA : functional adenoma, TS : tumor size, SSE : suprasellar extension

Table 4. Comparison of groups according to TS, SSE, Knosp grades in terms of resection degree

\begin{tabular}{|c|c|c|c|c|c|c|}
\hline & Total $(n=146)$ & Near-total $(n=47)$ & Subtotal $(n=36)$ & Biopsy $(n=7)$ & $x^{2}$ & $p$-value \\
\hline \multicolumn{7}{|c|}{ Resection $(n=236)$} \\
\hline TS & & & & & 92.164 & $<0.001^{*}$ \\
\hline $1(n=50)$ & $44(88.0)$ & $4(8.0)$ & $0(0.0)$ & $2(4.0)$ & & \\
\hline $2(n=75)$ & $63(84.0)$ & $7(9.3)$ & $4(5.3)$ & $1(1.3)$ & & \\
\hline $3(n=20)$ & $12(60.0)$ & $5(25.0)$ & $2(10.0)$ & $1(5.0)$ & & \\
\hline $4(n=58)$ & $24(41.4)$ & $15(25.9)$ & $17(29.3)$ & $2(3.4)$ & & \\
\hline $5(n=33)$ & $3(9.1)$ & $16(48.5)$ & $13(39.4)$ & $1(3.0)$ & & \\
\hline SSE & & & & & 59.680 & $<0.001^{*}$ \\
\hline$A(n=158)$ & $125(79.7)$ & $18(11.4)$ & $11(7.0)$ & $3(1.9)$ & & \\
\hline$B(n=46)$ & $18(39.1)$ & $16(34.8)$ & $10(21.7)$ & $2(4.3)$ & & \\
\hline$C(n=23)$ & $2(8.7)$ & $8(34.8)$ & $12(52.2)$ & $1(4.3)$ & & \\
\hline$D(n=9)$ & $0(0.0)$ & $5(55.6)$ & $3(33.3)$ & $1(11.1)$ & & \\
\hline Knosp & & & & & 85.382 & $<0.001^{*}$ \\
\hline $0(n=36)$ & $32(88.9)$ & $2(5.6)$ & $0(0.0)$ & $2(5.6)$ & & \\
\hline $1(n=75)$ & $63(84.0)$ & $5(6.7)$ & $7(9.3)$ & $0(0.0)$ & & \\
\hline $2(n=55)$ & $33(60.0)$ & $13(23.6)$ & $7(12.7)$ & $2(3.6)$ & & \\
\hline $3(n=40)$ & $16(40.0)$ & $12(30.0)$ & $10(25.0)$ & $2(5.6)$ & & \\
\hline $4(n=30)$ & $2(6.7)$ & $15(50.0)$ & $12(40.0)$ & $1(3.3)$ & & \\
\hline
\end{tabular}

Values are presented as number (\%). Fisher exact chi square. ${ }^{*} p<0.01$. TS : tumor size, SSE : suprasellar extension 
Table 5. Comparison of groups according to Knosp grades $0 / 1 / 2$ and $3 / 4$ in terms of resection degree

\begin{tabular}{|c|c|c|c|c|}
\hline & Knosp 0/1/2 & Knosp 3/4 & $x^{2}$ & $p$-value \\
\hline \multicolumn{5}{|c|}{ Resection $(\mathrm{n}=236)$} \\
\hline Total & $128(77.1)$ & $18(25.7)$ & 56.032 & $<0.001$ \\
\hline Near-total & $20(12.0)$ & 17 (38.6) & & \\
\hline Subtotal & $14(8.4)$ & $22(31.4)$ & & \\
\hline Biopsy & $4(2.4)$ & $3(4.3)$ & & \\
\hline
\end{tabular}

Values are presented as number (\%). Fisher exact chi square

higher than that of patients with near-total resection $(\mathrm{z}=6.44$, $p<0.001$ ), subtotal resection ( $\mathrm{z}=6.81, p<0.001)$, and biopsy $(\mathrm{z}=2.99, p=0.002)$. Moreover, the rate of patients who underwent total resection was significantly lower than that of those who underwent near-total and subtotal resection among those with SSE grade B (near total : $\mathrm{z}=3.40, p<0.001$; subtotal : $\mathrm{z}=2.30, p=0.02$ ), grade $\mathrm{C}$ (near total : $\mathrm{z}=4.21, p<0.001$; subtotal : $\mathrm{z}=6.44, p<0.001$ ), and grade $\mathrm{D}$ (near total $: \mathrm{z}=3.99, p<0.001$; subtotal : $\mathrm{z}=3.51, p<0.001$; biopsy $: \mathrm{z}=4.58, p<0.001$; Table 4$)$.

Based on Knosp classification, there was a significant difference regarding the amount of resection $\left(x^{2}=56.032, p<0.001\right)$. Subgroups were compared using a Z-test with a Bonferroni correction $(p<0.01)$. The proportion of total resection achievement among patients with Knosp grades 0, 1, and 2 adenomas was significantly higher than those with Knosp grades 3 and 4 $(\mathrm{z}=7.42, p<0.001$; Table 5) adenomas.

In this study, a total of 252 operations were performed, and the number of operations per patient ranged from 1-3 (mean, $1.07 \pm 0.27$; median, 1 ). We also evaluated the intraoperative and postoperative complications (Table 6).

The presence of rhinorrhea or diabetes insipidus (DI) complications between-groups did not differ according to the TS, SSE, or Knosp classifications ( $p>0.05$; Tables 7 and 8 ).

\section{DISCUSSION}

Since the first report of endonasal endoscopic resection of pituitary adenoma by Jankowski et al. ${ }^{19)}$ in 1992, remarkable progress has been made in the treatment of sellar lesions ${ }^{4,29)}$. Unlike microscopic surgery, endoscopic surgery has a longer learning curve ${ }^{4}$. In this study, we compared the preoperative MRI invasion parameters, as well as resection, remission, and complication rates for 236 patients who underwent endoscop-
Table 6. Complications

\begin{tabular}{|c|c|}
\hline & Value \\
\hline Total & 236 \\
\hline \multicolumn{2}{|l|}{ Insufficiency } \\
\hline No & $200(84.7)$ \\
\hline Yes & $36(15.3)$ \\
\hline \multicolumn{2}{|l|}{ Meningitis } \\
\hline No & $229(97.0)$ \\
\hline Yes & $7(3.0)$ \\
\hline \multicolumn{2}{|l|}{ Diabetes insipidus } \\
\hline No & $220(93.2)$ \\
\hline Temporary & $14(5.9)$ \\
\hline Permanent & $2(0.9)$ \\
\hline \multicolumn{2}{|l|}{ Epistaxis } \\
\hline No & $227(96.2)$ \\
\hline Temporary & $9(3.8)$ \\
\hline \multicolumn{2}{|l|}{ Rhinorrhea } \\
\hline No & $217(91.9)$ \\
\hline Temporary & $19(8.1)$ \\
\hline \multicolumn{2}{|l|}{ Rhinorrhea treatment method } \\
\hline No & $217(91.7)$ \\
\hline Follow-up with LD & $2(0.9)$ \\
\hline Follow-up with surgery & $5(2.1)$ \\
\hline Follow-up with LD+surgery & $12(5.1)$ \\
\hline \multicolumn{2}{|l|}{ Mortality } \\
\hline No & 235 (99.7) \\
\hline Yes & $1(0.3)$ \\
\hline
\end{tabular}

Values are presented as number (\%). LD : lumbar drainage

ic surgery for pituitary adenomas.

Pituitary adenomas tend to follow the least resistant pathway and grow primarily in structures such as the sphenoid sinus, suprasellar region, and cavernous sinus ${ }^{28}$. Cavernous sinus in- 
J Korean Neurosurg Soc 64 | July 2021

Table 7. Comparison of groups TS, SSE, and Knosp grades in terms of rhinorrhea

\begin{tabular}{|c|c|c|c|c|}
\hline & No $(n=217)$ & Yes $(n=19)$ & $x^{2}$ & $p$-value \\
\hline \multicolumn{5}{|c|}{ Rhinorrhea $(n=236)$} \\
\hline TS & & & 3.921 & 0.403 \\
\hline $1(n=50)$ & $48(96.0)$ & $2(4.0)$ & & \\
\hline $2(n=75)$ & $67(89.3)$ & $8(10.7)$ & & \\
\hline $3(n=20)$ & $17(85.0)$ & $3(15.0)$ & & \\
\hline $4(n=58)$ & $55(94.8)$ & $3(5.2)$ & & \\
\hline $5(n=33)$ & $30(90.9)$ & $3(9.1)$ & & \\
\hline SSE & & & 1.614 & 0.605 \\
\hline$A(n=158)$ & $146(92.9)$ & $11(7.1)$ & & \\
\hline$B(n=46)$ & $42(91.3)$ & $4(8.7)$ & & \\
\hline$C(n=23)$ & $20(86.9)$ & $3(13.1)$ & & \\
\hline$D(n=9)$ & $9(100.0)$ & $0(0.0)$ & & \\
\hline Knosp & & & 4.121 & 0.375 \\
\hline $0(n=36)$ & $31(86.1)$ & $5(13.9)$ & & \\
\hline $1(n=75)$ & $72(96.0)$ & $3(4.0)$ & & \\
\hline $2(n=55)$ & $51(92.7)$ & $4(7.3)$ & & \\
\hline $3(n=40)$ & $36(90.0)$ & $4(10.0)$ & & \\
\hline $4(n=30)$ & $27(90.0)$ & $3(10.0)$ & & \\
\hline
\end{tabular}

Values are presented as number (\%). Fisher exact chi square. TS : tumor size, SSE : suprasellar extension

Table 8. Comparison of groups according to TS, SSE, and Knosp grades in terms of diabetes insipidus

\begin{tabular}{|c|c|c|c|c|c|}
\hline & No $(n=220)$ & Temporary $(n=14)$ & Permanent $(n=2)$ & $x^{2}$ & $p$-value \\
\hline \multicolumn{6}{|c|}{ Diabetes insipidus $(\mathrm{n}=236)$} \\
\hline TS & & & & 5.658 & 0.691 \\
\hline $1(n=50)$ & $45(90.0)$ & $5(10.0)$ & $0(0.0)$ & & \\
\hline $2(n=75)$ & $69(92.0)$ & $4(5.3)$ & $2(2.7)$ & & \\
\hline $3(n=20)$ & $20(100.0)$ & $0(0.0)$ & $0(0.0)$ & & \\
\hline $4(n=58)$ & $54(93.1)$ & $4(6.9)$ & $0(0.0)$ & & \\
\hline $5(n=33)$ & $32(97.0)$ & $1(3.0)$ & $0(0.0)$ & & \\
\hline SSE & & & & 1.906 & 1.000 \\
\hline$A(n=158)$ & $146(92.4)$ & $10(6.3)$ & $2(1.3)$ & & \\
\hline$B(n=46)$ & $43(93.5)$ & $3(6.5)$ & $0(0.0)$ & & \\
\hline$C(n=23)$ & $22(95.6)$ & $1(4.4)$ & $0(0.0)$ & & \\
\hline$D(n=9)$ & $9(100.0)$ & $0(0.0)$ & $0(0.0)$ & & \\
\hline Knosp & & & & 9.638 & 0.159 \\
\hline $0(n=36)$ & $30(83.3)$ & $5(13.9)$ & $1(2.8)$ & & \\
\hline $1(n=75)$ & 70 (93.3) & $5(6.7)$ & $0(0.0)$ & & \\
\hline $2(n=55)$ & $54(98.1)$ & $1(1.9)$ & $0(0.0)$ & & \\
\hline $3(n=40)$ & $37(92.5)$ & $2(5.0)$ & $1(2.5)$ & & \\
\hline $4(n=30)$ & $29(96.7)$ & $1(3.3)$ & $0(0.0)$ & & \\
\hline
\end{tabular}

Values are presented as number (\%). Fisher exact chi square. TS : tumor size, SSE : suprasellar extension 
vasion is of particular importance because it is associated with the degree of surgical resection, hormonal remission, and serious complications ${ }^{33,34)}$. Thus, histological examination and surgical observation remain important for evaluating cavernous sinus invasion, though it is difficult to achieve consensus and concurrently apply these methods at all times ${ }^{10,14)}$. In this context, Knosp et al. ${ }^{25}$ classifications of cavernous sinus invasion are an important parameter used for radiological pre- and postoperative follow-up ${ }^{26}$.

In a recent case series by Dhandapani et al." where the only endoscopy was performed, the percentages of patients who underwent total resection were $90.6 \%$ among patients with Knosp grade 0 and 1, 82.1\% among those with Knosp grade 2, and $67.9 \%$ among those with Knosp grade 3 adenomas. Dallapiazza et al. ${ }^{6}$ reported a total resection rate of $89 \%$ among patients with Knosp grade 0, 1, and 2, and 28\% among those with Knosp grade 3 and 4 . In our study, the total resection rate was $85.5 \%$ for patients with Knosp grades 0 and 1, while for patients with Knosp grades 0, 1, and 2, the total resection rate was $77.1 \%$, and the total/near-total resection rate was $89.1 \%$. In patients with Knosp grades 3 and 4, the total resection rate was $25.7 \%$, and the total/near-total resection rate was $64.2 \%$. The main reason for the differences between total and neartotal resection rates among patients with Knosp grades 3 and 4 adenomas is the residual tumor tissue remained in the cavernous sinus. Based on Knosp classification, the resection rates in our study are comparable with those in the literature.

Since Knosp classification alone is not sufficient to predict the resectable of the tumor, SSE and TS classifications might be separate indicators, and in some cases, they can give an idea independently of Knosp classification ${ }^{25}$. In support of this, Kim et al. ${ }^{23)}$ reported a 2.29-fold increase in the likelihood of residual growth for each grade increase in TS and a 3.12-fold increase for each Knosp grade.

In our study, the total resection rate was $82 \%$ among patients with TS grade 1, 2, and 3 tumors, and $29.6 \%$ among those with TS grade 4 and 5 tumors. The near-total resection rate was $63.7 \%$ among the latter. Dallapiazza et al. ${ }^{6}$ reported a gross-total resection rate of $78 \%$ for tumors smaller than $3 \mathrm{~cm}$, and 54\% for tumors larger than $3 \mathrm{~cm}$ (60-108 months).

In the study conducted by Kim et al. ${ }^{23}$, the classification based on tumor length for NFA adenomas was examined in terms of gross-total resection rates; $100 \%$ for TS grade 1 , 92.9\% for TS grade 2, 86\% for TS grade 3, 65.5\% for TS grade
4 , and $55.6 \%$ for TS grade 5 tumors. In our study, the respective total resection rates were $88 \%, 84 \%, 60 \%, 41 \%$, and $9 \%$, while the total/near-total resection rates were $96 \%, 93.3 \%$, $85 \%, 67.2 \%$, and $57.5 \%$ for grades 1 to 5 , respectively. In the study conducted by Gondim et al. ${ }^{17}$, the total resection rate was $38 \%$, and the total/near-total resection rate was $56 \%$ for tumors larger than $4 \mathrm{~cm}$. In the study conducted by Juraschka et al. ${ }^{22}$, the total/near-total resection rate was $44 \%$ for tumors larger than $3 \mathrm{~cm}$. In our study, the tumor resection rates based on the TS and SSE classifications were similar to those reported in the literature. In addition, we found that the comparison of the SSE and TS classifications yielded similar results in terms of remission and resection rates.

Tumor volume is also associated with achieving remission in hormone-secreting adenomas. In the study conducted by Akin et al. ${ }^{1)}$, the remission rate in patients with $0-1 \mathrm{~cm}$ prolactin-secreting adenomas was $73.7 \%$ and $45.1 \%$ for those with adenomas larger than $1 \mathrm{~cm}$. In the study conducted by Anik et al. ${ }^{2}$, the remission rates for patients with Knosp grade 3 and 4 GH-secreting adenomas were $40.7 \%$ and $24 \%$ for those with Knosp grade 4 adenomas. The same study reported an $81.3 \%$ remission rate for patients with $\mathrm{GH}$-secreting adenomas smaller than $1 \mathrm{~cm}$ and $63.3 \%$ for those larger than $1 \mathrm{~cm}$.

In a review by Broersen et al. ${ }^{3)}$ on Cushing's disease, an $83.9 \%$ remission rate was reported among patients with adenomas of $0-1 \mathrm{~cm}$ in size and $76.3 \%$ among those with adenomas greater than $1 \mathrm{~cm}$. Further, a review by Dhandapani et al. ${ }^{9)}$ reported that the remission rate in patients with pure endoscopic FA was $84 \%$ among those without cavernous sinus invasion, and $42 \%$ among those with cavernous invasion. In our study, the remission rates in patients with FA were $84.7 \%$ among those with TS grade 1 and $80.3 \%$ among those with TS grade $2-5$. However, the remission rate decreased to $60.7 \%$ among patients with FAs greater than $2 \mathrm{~cm}$ in length (TS grades 3-5). In the literature, FAs are generally grouped as macro and microadenomas with a cut-off of $1 \mathrm{~cm}$. When we evaluated the subgroups of adenomas according to their size, statistically significantly lower remission rates were found for adenomas greater than $2 \mathrm{~cm}$ (TS grades 3-5). While the remission rate was found to be $84 \%$ in patients with SSE grade $\mathrm{A}$, it decreased to $46.1 \%$ in adenomas that were $1 \mathrm{~cm}$ larger according to the SSE classification (SSE grades B, C, and D). Moreover, the remission rate in patients with FA was 88.2\% among those with Knosp grades 0 , 1, and 2, but 45\% among 
those with Knosp grades 3 and 4 . These findings indicate that remission rates for patients with FA are closely related to TS and Knosp classifications. Our results were similar to those in the literature, whereas the remission rates were lower for adenomas greater than TS grade 2 and SSE grade B in our study.

The complication rates in our study were similar to those reported in previous studies. Specifically, the rate of pituitary hormonal insufficiency in our study was $15.3 \%$, similar to the $14.5 \%$ rate reported by de Divitiis et al. ${ }^{7}$. However, this was inconsistent with the study by Dehdashti et al. ${ }^{8}$, who reported a reported a rate of $3 \%$. Higher rates were reported in the giant pituitary adenoma series study by Gondim et al. ${ }^{17)}$ (36\%) and Cusimano et al. ${ }^{5)}$ (31\%). The rate of transient DI was 5.9\% in our study, while rates of $2.5-20 \%$ are reported in the literature $^{31)}$. The permanent DI rate was $0.9 \%$, while de Divitiis et al. ${ }^{7)}$ reported a rate of $3.1 \%$, and Gondim et al. ${ }^{15)}$ reported a $0.7 \%$ rate.

Regarding epistaxis, the rate was $3.8 \%$ in our study, while in other series by de Divitiis et al. ${ }^{7)}$ and Frank et al. ${ }^{11}$, the epistaxis rates were $1.7 \%$ and $0.7 \%$, respectively. Endoscopic transsphenoidal surgery is reported to be superior to microscopic transsphenoidal surgery in terms of sino-nasal complications, concerning the visual contribution of the endoscope at all stages of the surgery, the reduction of blind instrument maneuvers, and the absence of a speculum ${ }^{15,24,30)}$. Surgical experience and collaboration with otolaryngologist specialists were shown to reduce epistaxis rates ${ }^{24)}$. Since we did not receive close support from an otolaryngologist clinic, except in the first 15 cases in our study, we believe that this resulted in higher rates of epistaxis in patients at the beginning of our surgical experience, compared to the reported rates in the literature.

In the literature, the rate of cerebrospinal fluid leakage during operation is reported to be between 16 and $26 \%{ }^{4,32}$. However, the rates of postoperative rhinorrhea were $3.5 \%, 5 \%$, and $1.2 \%$ in the studies by Dehdashti et al. ${ }^{8)}$, Paluzzi et al. ${ }^{26)}$, and Frank et al. ${ }^{11}$, respectively, which included large samples of patients. Our rhinorrhea rates were higher than those reported in the literature, at $8.1 \%$. Two patients $(0.9 \%)$ with rhinorrhea were treated with lumbar drainage; five (2.1\%) underwent surgical repair using a subcutaneous fat tissue and fascia graft; 12 patients (5.1\%) underwent a combination of surgery and lumbar drainage. The meningitis rate was $3 \%$ in our study, also higher than the $1 \%$ rate reported by Dehdashti et al. ${ }^{8)}$ and $0.4 \%$ rate reported by de Divitiis et al. ${ }^{7}$. The higher rate of meningitis in our study may be explained by the higher rate of rhinorrhea compared to those reported in the literature.

Although internal carotid artery injury is rare, it has serious consequences for mortality and morbidity. In our study, one patient $(0.3 \%)$ with recurrent adenoma who underwent microscopic transsphenoidal pituitary surgery died due to meningitis-related complications and post-operative intracerebral hematoma and subsequent rhinorrhea. Mortality due to various reasons after endoscopic pituitary surgery has been reported to range between $0-0.7 \%{ }^{15,21)}$.

This study included 236 patients from a single-center. For the first 100 cases especially, we acted selectively to avoid possible cases with complications, as well as insufficient and incomplete surgery, which might have affected our results. One of the limitations of our study is that the Knosp, TS, and SSE grades were measured based on the two-dimensional tumor length rather than tumor volume. Therefore, the absence of volumetric measurements may have influenced the resection rate.

\section{CONCLUSION}

Our study showed that the resection and remission rates of FAs are directly proportional to the size of the adenoma and Knosp grade, in line with what has previously been reported. However, an interesting finding of our study is that an adenoma size of $2 \mathrm{~cm}$ seems to be a better cut-off point to predict remission and resection rates than an adenoma size of $1 \mathrm{~cm}$. Additionally, suprasellar tumor extension less than $1 \mathrm{~cm}$ was also found to be a predictor of favorable remission and resection rates. These findings need to be verified by further studies with larger sample size with longer follow-up periods.

\section{CONFLICTS OF INTEREST}

No potential conflict of interest relevant to this article was reported.

\section{INFORMED CONSENT}

This type of study does not require informed consent. 


\section{AUTHOR CONTRIBUTIONS}

\author{
Conceptualization : BE, OG \\ Data curation : BE, OB, AA, EA, YSA, OT \\ Formal analysis : BE, OB, AA, EA, YSA, OT \\ Funding acquisition : $B E, O G$ \\ Methodology: BE, AA, YSA, OT, OG \\ Project administration : BE, OB, AA, EA, YSA, OT \\ Visualization: BE, OB, AA, EA, YSA \\ Writing - original draft : $\mathrm{BE}, \mathrm{OB}, \mathrm{AA}, \mathrm{EA}, \mathrm{YSA}, \mathrm{OT}$ \\ Writing - review \& editing : BE, OG
}

\section{ORCID}

\begin{abstract}
Buruc Erkan
https://orcid.org/0000-0001-8586-0613

Ozan Barut

https://orcid.org/0000-0001-6572-9589

Ahmet Akbas

https://orcid.org/0000-0001-6939-5803

Ebubekir Akpinar https://orcid.org/0000-0002-4069-0021

Yasemin Sefika Akdeniz https://orcid.org/0000-0002-9740-6167

Osman Tanriverdi https://orcid.org/0000-0002-4846-4213

Omur Gunaldi https://orcid.org/0000-0001-5071-1319
\end{abstract}

\section{- Acknowledgements}

We would like to pay our gratitude and respects to our colleague, Dr. Ahmet Akbas. After his valuable participance in this study, Dr. Ahmet Akbas passed away in October 7 of 2020 due to COVID-19 related symptoms at the age of 31 . He was a dedicated neurosurgeon with a great passion in science and surgery, and a beloved father and husband. He certainly will be in our thoughts for the rest of our works and life.

\section{References}

1. Akin S, Isikay I, Soylemezoglu F, Yucel T, Gurlek A, Berker M : Reasons and results of endoscopic surgery for prolactinomas: 142 surgical cases. Acta Neurochir (Wien) 158 : 933-942, 2016

2. Anik I, Cabuk B, Gokbel A, Selek A, Cetinarslan B, Anik Y, et al. : Endoscopic transsphenoidal approach for acromegaly with remission rates in 401 patients: 2010 consensus criteria. World Neurosurg 108 : 278290, 2017

3. Broersen LHA, Biermasz NR, van Furth WR, de Vries F, Verstegen MJT, Dekkers OM, et al. : Endoscopic vs. microscopic transsphenoidal surgery for Cushing's disease: a systematic review and meta-analysis. Pituitary
$21: 524-534,2018$

4. Chi F, Wang Y, Lin Y, Ge J, Qiu Y, Guo L : A learning curve of endoscopic transsphenoidal surgery for pituitary adenoma. J Craniofac Surg 24 : 2064-2067, 2013

5. Cusimano MD, Kan P, Nassiri F, Anderson J, Goguen J, Vanek I, et al. : Outcomes of surgically treated giant pituitary tumours. Can J Neurol Sci 39 : 446-457, 2012

6. Dallapiazza RF, Grober Y, Starke RM, Laws ER Jr, Jane JA Jr : Long-term results of endonasal endoscopic transsphenoidal resection of nonfunctioning pituitary macroadenomas. Neurosurgery $76:$ 42-53, 2015

7. de Divitiis E, Cappabianca P, Cavallo LM : Endoscopic endonasal transsphenoidal approach to the sellar region in de Divitiis $E$, Cappabianca $P$ (eds) : Endoscopic Endonasal Transsphenoidal Surgery. Vienna : Springer, 2003, pp91-130

8. Dehdashti AR, Ganna A, Karabatsou K, Gentili F : Pure endoscopic endonasal approach for pituitary adenomas: early surgical results in 200 patients and comparison with previous microsurgical series. Neurosurgery 62 : 1006-1015; discussion 1015-1017, 2008

9. Dhandapani S, Singh H, Negm HM, Cohen S, Anand VK, Schwartz TH : Cavernous sinus invasion in pituitary adenomas: systematic review and pooled data meta-analysis of radiologic criteria and comparison of endoscopic and microscopic surgery. World Neurosurg 96 : 36-46, 2016

10. Diao $Y$, Liang $L, Y u C$, Zhang $M$ : Is there an identifiable intact medial wall of the cavernous sinus? Macro- and microscopic anatomical study using sheet plastination. Neurosurgery 73 : ons106-ons110, 2013

11. Frank G, Pasquini E, Farneti G, Mazzatenta D, Sciarretta V, Grasso V, et al. : The endoscopic versus the traditional approach in pituitary surgery. Neuroendocrinology 83 : 240-248, 2006

12. García S, Reyes L, Roldán P, Torales J, Halperin I, Hanzu F, et al. : Does low-field intraoperative magnetic resonance improve the results of endoscopic pituitary surgery? Experience of the implementation of a new device in a referral center. World Neurosurg 102 : 102-110, 2017

13. Giustina A, Chanson P, Bronstein MD, Klibanski A, Lamberts S, Casanueva FF, et al. : A consensus on criteria for cure of acromegaly. J Clin Endocrinol Metab 95 : 3141-3148, 2010

14. Gonçalves MB, de Oliveira JG, Williams HA, Alvarenga RM, Landeiro JA : Cavernous sinus medial wall: dural or fibrous layer? Systematic review of the literature. Neurosurg Rev 35 : 147-154, 2012

15. Gondim JA, Schops M, de Almeida JP, de Albuquerque LA, Gomes E, Ferraz $\mathrm{T}$, et al. : Endoscopic endonasal transsphenoidal surgery: surgical results of 228 pituitary adenomas treated in a pituitary center. Pituitary $13: 68-77,2010$

16. Gondim JA, Almeida JP, Albuquerque LA, Schops M, Gomes E, Ferraz T, et al. : Endoscopic endonasal approach for pituitary adenoma: surgical complications in 301 patients. Pituitary 14 : 174-183, 2011

17. Gondim JA, Almeida JP, Albuquerque LA, Gomes EF, Schops M : Giant pituitary adenomas: surgical outcomes of 50 cases operated on by the endonasal endoscopic approach. World Neurosurg 82 : e281-e290, 2014

18. Haliloglu O, Kuruoglu E, Ozkaya HM, Keskin FE, Gunaldi O, Oz B, et al. : 
Multidisciplinary approach for acromegaly: a single tertiary center's experience. World Neurosurg 88 : 270-276, 2016

19. Jankowski R, Auque J, Simon C, Marchal JC, Hepner H, Wayoff M : How I do it: head and neck and plastic surgery: endoscopic pituitary tumor surgery. Laryngoscope 102 : 198-202, 1992

20. Jho HD, Carrau RL : Endoscopic endonasal transsphenoidal surgery: experience with 50 patients. J Neurosurg 87 : 44-51, 1997

21. Jho HD : Endoscopic transsphenoidal surgery. J Neurooncol 54 : 187195, 2001

22. Juraschka K, Khan $\mathrm{OH}$, Godoy BL, Monsalves E, Kilian A, Krischek B, et al. : Endoscopic endonasal transsphenoidal approach to large and giant pituitary adenomas: institutional experience and predictors of extent of resection. J Neurosurg $121:$ 75-83, 2014

23. Kim JH, Lee JH, Lee JH, Hong AR, Kim YJ, Kim YH : Endoscopic transsphenoidal surgery outcomes in 331 nonfunctioning pituitary adenoma cases after a single surgeon learning curve. World Neurosurg 109 : e409-e416, 2018

24. Kiraz M, Gunaldi O, Tanriverdi O, Erdim I, Postalci LS, Tugcu B, et al. : Comparison of sinonasal complications of microscopic and endoscopic approaches for transsphenoidal hypophyseal surgery: prospective study. Turk Neurosurg $28:$ 915-922, 2018

25. Knosp E, Steiner E, Kitz K, Matula C : Pituitary adenomas with invasion of the cavernous sinus space: a magnetic resonance imaging classification compared with surgical findings. Neurosurgery $33: 610-618$, 1993

26. Paluzzi A, Fernandez-Miranda JC, Tonya Stefko S, Challinor S, Snyderman CH, Gardner PA : Endoscopic endonasal approach for pituitary adenomas: a series of 555 patients. Pituitary 17 : 307-319, 2014

27. Phan K, Xu J, Reddy R, Kalakoti P, Nanda A, Fairhall J : Endoscopic endonasal versus microsurgical transsphenoidal approach for growth hormone-secreting pituitary adenomas-systematic review and metaanalysis. World Neurosurg 97 : 398-406, 2017

28. Ramakrishnan VR, Suh JD, Lee JY, O'Malley BW Jr, Grady MS, Palmer JN : Sphenoid sinus anatomy and suprasellar extension of pituitary tumors. J Neurosurg $119: 669-674,2013$

29. Rudnik A, Zawadzki T, Wojtacha M, Bazowski P, Gamrot J, GaluszkaIgnasiak $B$, et al. : Endoscopic transnasal transsphenoidal treatment of pathology of the sellar region. Minim Invasive Neurosurg 48 : 101107, 2005

30. Singh H, Essayed WI, Cohen-Gadol A, Zada G, Schwartz TH : Resection of pituitary tumors: endoscopic versus microscopic. J Neurooncol 130 : 309-317, 2016

31. Tabaee A, Anand VK, Barrón Y, Hiltzik DH, Brown SM, Kacker A, et al. : Endoscopic pituitary surgery: a systematic review and meta-analysis. J Neurosurg $111:$ 545-554, 2009

32. Tamašauskas A, Šinkūnas $K$, Draf W, Deltuva $V$, Matukevičius A, Rastenytė $D$, et al. : Management of cerebrospinal fluid leak after surgical removal of pituitary adenomas. Medicina (Kaunas) 44 : 302-307, 2008

33. Taniguchi M, Hosoda K, Akutsu N, Takahashi Y, Kohmura E : Endoscopic endonasal transsellar approach for laterally extended pituitary adenomas: volumetric analysis of cavernous sinus invasion. Pituitary 18 : 518-524, 2015

34. Woodworth GF, Patel KS, Shin B, Burkhardt JK, Tsiouris AJ, McCoul ED, et al. : Surgical outcomes using a medial-to-lateral endonasal endoscopic approach to pituitary adenomas invading the cavernous sinus. J Neurosurg 120 : 1086-1094, 2014 